\title{
Effects of Suvorexant, a Dual Orexin/Hypocretin Receptor Antagonist, on Impulsive Behavior Associated with Cocaine
}

\author{
Taylor A Gentile', Steven J Simmons', Mia N Watson', Krista L Connelly', Eugen Brailoiu', Yanan Zhang ${ }^{2}$ and \\ John W Muschamp*,I
}

'Center for Substance Abuse Research, Lewis Katz School of Medicine, Temple University, Philadelphia, PA, USA; ${ }^{2}$ Research Triangle Institute, Research Triangle Park, NC, USA

\begin{abstract}
Hypothalamic hypocretin (orexin) peptides mediate arousal, attention, and reward processing. Fibers containing orexins project to brain structures that govern motivated behavior, including the ventral tegmental area (VTA). A number of psychiatric conditions, including attention deficit hyperactivity disorder (ADHD) and substance use disorders, are characterized by deficits in impulse control, however the relationship between orexin and impulsive behavior is incompletely characterized. The effects of systemic or centrally administered orexin receptor $(\mathrm{OXR})$ antagonists on measures of impulsive-like behavior in rats were evaluated using the five-choice serial reaction time task (5-CSRTT) and delay discounting procedures. These paradigms were also used to test the capacity of OXR antagonists to attenuate acute cocaine-evoked impulsivity. Finally, immunohistochemistry and calcium imaging were used to assess potential cellular mechanisms by which OXR blockade may influence motor impulsivity. Suvorexant, a dual $\left(O X_{1 / 2} R\right)$ orexin receptor antagonist, reduced cocaine-evoked premature responses in 5-CSRTT when administered systemically or directly into VTA. Neither suvorexant nor OX, R- or OX ${ }_{2} \mathrm{R}$-selective compounds (SB334867 or TCS-OX2-29, respectively) altered delay discounting. Finally, suvorexant did not alter Fos-immunoreactivity within tyrosine hydroxylase-immunolabeled neurons of VTA, but did attenuate cocaine- and orexin-induced increases in calcium transient amplitude within neurons of VTA. Results from the present studies suggest potential therapeutic utility of OXR antagonists in reducing psychostimulant-induced motor impulsivity. These findings also support the view that orexin transmission is closely involved in executive function in normal and pathological conditions.

Neuropsychopharmacology (2018) 43, I00I-1009; doi:I0.1038/npp.2017.158; published online 16 August 2017
\end{abstract}

\section{INTRODUCTION}

The hypocretin (orexin) system consists of two excitatory neuropeptides (hypocretin-1/orexin A and hypocretin-2/ orexin B) expressed by neurons of the hypothalamus that innervate a number of targets, including the ventral tegmental area (VTA), dorsal raphe nucleus, and locus coeruleus (de Lecea et al, 1998; Peyron et al, 1998; Sakurai et al, 1998). Accordingly, these brain structures show high levels of the peptides' cognate G-protein-coupled receptors, $\mathrm{OX}_{1} \mathrm{R}$ and $\mathrm{OX}_{2} \mathrm{R}$ (de Lecea et al, 1998; Marcus et al, 2001; Sakurai et al, 1998; Zhu et al, 2003). Hypothalamic orexin neurons are in this way positioned to engender goal-directed behaviors (eg, feeding, mating, and drug-seeking) that are in turn regulated by monoamine transmitters (ie, dopamine, serotonin, and norepinephrine) native to these brainstem nuclei (Borgland et al, 2009; Harris et al, 2005; Muschamp et al, 2007; Sakurai, 2014). This is accomplished in part by

\footnotetext{
*Correspondence: Dr JW Muschamp, Center for Substance Abuse Research, Department of Pharmacology, Lewis Katz School of Medicine, Temple University, 3500 North Broad Street - MERB 849, Philadelphia, PA, 19|40, USA, Tel: + I 2157078089 , Fax: + I 2157076661 , E-mail: john.muschamp@temple.edu

Received 28 March 2017; revised 10 July 2017; accepted 16 July 2017; accepted article preview online 25 July 2017
}

modulating aminergic transmission in forebrain circuits that are critical for sustained attention and executive function, such as projections from prefrontal cortex to ventral striatum (Dalley et al, 2008; Ongur and Price, 2000). While this anatomical arrangement suggests that orexin transmission is plausibly involved in impulsive behavior, only a few reports have addressed this question, and a clear picture has not yet emerged (Boschen et al, 2009; Lambe et al, 2005; Muschamp et al, 2014).

Defined as a tendency to engage in behaviors without forethought (Evenden, 1999), impulsivity is apparent across psychiatric diagnostic categories and can lead to poorer outcomes in patients with attention deficit hyperactive disorder (ADHD), bipolar disorder, and substance use disorders (de Wit, 2009; Kessler et al, 2014; LopezTorrecillas et al, 2014; Swann, 2010; Vall et al, 2015). The putative relationship between motivated behavior and orexin transmission support targeting orexin receptors for therapeutic intervention. The recent approval for clinical use of the $\mathrm{OX}_{1} \mathrm{R} / \mathrm{OX}_{2} \mathrm{R}$ antagonist suvorexant in the treatment of insomnia raises the question of whether this compound may also be valuable in treating psychiatric disorders characterized by high levels of impulsivity (Khoo and Brown, 2014; Roecker et al, 2016; Scammell and Winrow, 2011). The present study sought to assess the potential therapeutic utility 
of suvorexant as well as subtype-selective OXR antagonists in two rodent models of impulsivity, the five-choice serial reaction time (5-CSRTT) and delay discounting tasks (Winstanley et al, 2006). Previous studies demonstrate reduced motor impulsivity following pre-treatment with a selective $\mathrm{OX}_{1} \mathrm{R}$ antagonist before 5-CSRTT (Muschamp et al, 2014). To gain further insight into the functional neuroanatomy that may underlie effects of OXR blockade on impulsive behaviors, we performed direct infusions of suvorexant within VTA, a DA-rich principal target of orexin afferents (Fadel and Deutch, 2002; Peyron et al, 1998). In addition, we assessed how orexin receptor blockade altered Fos immunoreactivity (ir) within DA-producing neurons of VTA and further how suvorexant influences orexin-and cocaine-evoked calcium transients within VTA neurons in vitro.

\section{MATERIALS AND METHODS}

\section{Animals}

Male Sprague-Dawley rats (Charles River) arrived at Temple University's vivarium $\sim 60$ days old, were pair-housed and food-restricted to $85 \%$ of their free-fed bodyweight. Rats were acclimated for at least 1 wk. All experimental procedures were approved by Temple University's Institutional Animal Care and Use Committee.

\section{Drugs}

For all experiments, suvorexant (SelleckChem, Munich, Germany), SB334867, and TCS-OX2-29 (provided by Dr Yanan Zhang, Research Triangle Institute, NC) were dissolved in dimethyl sulfoxide (DMSO) and administered at $0.3 \mathrm{ml} / \mathrm{kg}$ (i.p), or $200 \mathrm{nl}$ when bilaterally injected into VTA (100 nl/ hemisphere). Cocaine hydrochloride (Sigma Chemical Company, St. Louis, MO) was dissolved in $0.9 \%$ physiological saline and administered at $1.0 \mathrm{ml} / \mathrm{kg}$ (i.p.). Orexin A was purchased from American Peptide Inc. (Sunnyvale, CA).

\section{Surgical Procedure}

General anesthesia was induced and maintained with 2-5\% isoflurane in oxygen (flow rate: $1.5 \mathrm{l} / \mathrm{min}$ ). Rats were implanted with bilateral stainless steel guide cannulae (22 G, $8.5 \mathrm{~mm}$ in length) into VTA (from bregma in $\mathrm{mm}$ : AP -5.4; $\mathrm{ML} \pm 2.1$ at $10^{\circ}$ angle; $\mathrm{DV}-6.8$ ). Stainless-steel obdurators ( $28 \mathrm{G}, 8.5 \mathrm{~mm}$ in length) were kept in guide cannulae to maintain their patency. When ready for VTAdirected injections, internal cannulae $(28 \mathrm{G}, 9.5 \mathrm{~mm}$ in length) were used for injections (Plastics One, Roanoke, VA).

\section{Experimental Procedures}

Experiment 1: 5-choice serial reaction time task (5-CSRTT). Rats were trained in computer-controlled operant chambers housed inside ventilated, sound-attenuating cabinets (Med Associates, St. Albans, VT). Chambers were fitted with 5 internally illuminated apertures monitored by infrared detectors. The opposite wall contained an illuminated food hopper equipped with an infrared detector (Supplementary Figure 1). Rats were trained daily for 90 trials or for $30 \mathrm{~min}$ and received either a sucrose pellet ( $45 \mathrm{mg}$; Bio-Serv,
Flemington, NJ) for a correct response (poking illuminated aperture) or a 'time-out' period in which the house light was turned off after an incorrect, premature, or omitted response. After rats achieved $\geq 70 \%$ correct, and $\leqslant 15 \%$ omitted responses across four consecutive daily sessions, drug treatment sessions began. Here, suvorexant or TCS-OX2-29 $(0,3,10$, or $30 \mathrm{mg} / \mathrm{kg})$ was administered $30 \mathrm{~min}$ before testing and, in subsequent sessions, cocaine ( 0 or $3 \mathrm{mg} / \mathrm{kg}$ ) was then administered $5 \mathrm{~min}$ before the start of testing. For direct site injections, suvorexant ( $3 \mu \mathrm{g}$ per hemisphere) was administered via 28-G injector cannulae attached to Hamilton syringes (Model 7101, Hamilton) using a precision pump (PHD 2000, Harvard Apparatus) at a rate of $100 \mathrm{nl} / \mathrm{min}$. Anatomical localization of injections to the VTA DA neuronal population was confirmed by immunohistochemical labeling for tyrosine hydroxylase $(\mathrm{TH})$ in midbrain sections collected after behavioral testing was concluded (Figure $3 \mathrm{~b}$ ).

Experiment 2: delay discounting. A separate cohort of rats was trained in chambers as described above. Rats were trained for 60 trials and received either a single sucrose pellet for a response associated with the small-reward option or four sucrose pellets for a response associated with the large-reward option following a 0-, 15-, 30-, or 45-s delay of selecting the left or right internally illuminated apertures. The left or right apertures were randomly assigned for each rat to administer a large or small reward. Sessions were divided into 4 blocks of 15 trials each with two 'forced-choice' trials at the start of each block. In forced-choice trials, left and right apertures were illuminated individually in alternate trials and rewarded after the same delay period used in ten subsequent free-choice trials in which both left and right apertures are illuminated simultaneously. Thus, a single, enforced exposure to reward contingencies preceded every block of trials. Only rats that responded in both forced choice trials were used, demonstrating familiarity with the paradigm and capacity for consistent responding under time-contingent conditions. After rats were trained and responded with $\geq 70 \%$ correct and $\leq 15 \%$ omissions across four consecutive sessions, drug treatments were administered according to a Latin square design. Suvorexant, TCS-OX2-29, or SB334867 (suvorexant; TCSOX2-29: 0, 3, 10, 30 mg/kg; SB334867: 0, 1, 3, $10 \mathrm{mg} / \mathrm{kg}$ ) was administered $30 \mathrm{~min}$ before and cocaine ( 0 or $3 \mathrm{mg} / \mathrm{kg}$ ) was administered $5 \mathrm{~min}$ before the delay discounting testing (Supplementary Figure 1D).

Experiment 3: $\mathrm{TH}$ and fos immunohistochemistry in $V T A$. To assess effects of OXR blockade on neuronal activation of DA-producing neurons in VTA, a behaviorally and pharmacologically naïve cohort of rats were administered suvorexant ( 0 or $30 \mathrm{mg} / \mathrm{kg}$, i.p.) $30 \mathrm{~min}$ prior to cocaine ( 0 or $3 \mathrm{mg} / \mathrm{kg}$ ) in their home cage. Ninety minutes following cocaine, rats were deeply anesthetized with a phenytoinphenobarbital cocktail (120 mg/kg, i.p.) and perfused with $\sim 100 \mathrm{ml}$ cold phosphate-buffered saline (PBS; 0.1M, pH 7.4) followed by $\sim 300 \mathrm{ml} 4 \%$ paraformaldehyde (PFA). Brains were post-fixed for $24 \mathrm{~h}$ in $4^{\circ} \mathrm{C}$ PFA followed by $72 \mathrm{~h}$ in $4{ }^{\circ} \mathrm{C}$ $30 \%$ sucrose and finally flash-frozen in 2-methyl butane chilled on dry ice. Brains were subsequently sectioned using a cryostat, and coronal sections $(40 \mu \mathrm{m})$, containing the entire VTA (from bregma: AP $-5.0 \mathrm{~mm}$ to $-6.5 \mathrm{~mm}$; Brain 
Maps III atlas available online: http://larrywswanson.com/) were collected.

For immunolabeling, tissue sections were washed in 0.1 $\mathrm{M}$ PBS, blocked in 5\% donkey serum in PBS with $0.3 \%$ Triton X-100 (PBS+) and incubated in primary antibody solution for $72 \mathrm{~h}$ at $4{ }^{\circ} \mathrm{C}$ (rabbit anti-cFos (1: 1,000; SC-52, Santa Cruz Biotechnology, Santa Cruz, CA) in 1.5\% donkey serum in PBS+). Sections were then incubated in secondary antibody solution for $3 \mathrm{~h}$ (donkey anti-rabbit AlexaFluor 555 (1:400; ThermoFisher, Waltham, MA) in 1.5\% donkey serum in PBS+). Sections underwent serial immunolabeling as above using rabbit anti-TH (1:1,000; AB-152, Millipore, Billerica, MA) primary antibody and donkey anti-rabbit AlexaFluor 488 (1:400; ThermoFisher)] secondary antibody.

All TH-ir neurons and Fos-ir nuclei that were visible in every third tissue section collected were counted by an experimenter blinded to treatment conditions using an Eclipse $80 i$ upright fluorescent microscope (Nikon) under $\times 10$ objective magnification (Supplementary Figure 3). Three sections were averaged together for counting. The percentage of $\mathrm{Fos}^{+}-\mathrm{TH}^{+}$neurons was calculated by: $\left[\left(\mathrm{TH}^{+}-\right.\right.$Fos $\left.^{+}\right) /\left(\right.$total $\left.\left.\mathrm{TH}^{+}\right) \times 100\right]$.

\section{Experiment 4: intracellular calcium measurement}

Neuronal cell culture. Neurons from the VTA were dissociated from neonatal (1-2-day old) Sprague Dawley rats (Ace Animal, Boyertown, PA) of both sexes as previously described (Barr et al, 2015). Newborn rats were decapitated, the brains removed surgically and immersed in ice-cold Hanks balanced salt solution (HBSS; Mediatech, Herndon, VA). The VTA was subjected to enzymatic digestion (papain, $37^{\circ} \mathrm{C}$ ) followed by mechanical trituration in presence of total medium - Neurobasal A (Invitrogen, Carlsbad, CA) containing 1\% GlutaMax (Invitrogen), 2\% penicillin-streptomycinamphotericin B solution (Mediatech) and 10\% fetal bovine serum. Cells were cultured on round $25 \mathrm{~mm}$ glass coverslips coated with poly-L-lysine (Sigma) in six-well plates. Cultures were maintained at $37^{\circ} \mathrm{C}$ in a humidified atmosphere with $5 \%$ $\mathrm{CO}_{2}$. The mitotic inhibitor cytosine $\beta$-arabinofuranoside ( $1 \mu \mathrm{M}$; Sigma) was added to the culture the third day to inhibit glial cell proliferation. Cells were used after 5 days in culture.

Calcium imaging. $\left[\mathrm{Ca}^{2+}\right]_{\mathrm{i}}$ was measured as previously described (Arslan et al, 2000; Barr et al, 2015). Cells were incubated with $5 \mu \mathrm{M}$ fura-2 AM (Invitrogen) in HBSS at room temperature for $45 \mathrm{~min}$ in the dark, washed three times with dye-free HBSS, and then incubated for another $45 \mathrm{~min}$ to allow for complete de-esterification of the dye. Coverslips ( $25 \mathrm{~mm}$ diameter) were subsequently mounted in an open bath chamber (RP-40LP, Warner Instruments; Hamden, CT) on the stage of an inverted microscope Nikon Eclipse TiE (Nikon; Melville, NY) equipped with a Perfect Focus System and a Photometrics CoolSnap HQ2 CCD camera (Photometrics, Tucson, AZ). During the experiments, the Perfect Focus System was activated. Fura-2 AM fluorescence $($ emission $=510 \mathrm{~nm})$, following alternate excitation at 340 and $380 \mathrm{~nm}$, was acquired at a frequency of $0.25 \mathrm{~Hz}$. Images were acquired and analyzed using NIS-Elements AR 3.1 software (Nikon). After appropriate calibration with ionomycin and $\mathrm{CaCl}_{2}$, and $\mathrm{Ca}^{2+}$ free and EGTA, respectively, the ratio of the fluorescence signals $(340 / 380 \mathrm{~nm})$ was converted to $\mathrm{Ca}^{2+}$ concentrations. In $\mathrm{Ca}^{2+}$-free experiments, $\mathrm{CaCl}_{2}$ was omitted. Calcium transients from VTA neurons were measured following application of orexin $A(10 \mathrm{nM})$, orexin A with cocaine $(10 \mu \mathrm{M})$, and orexin A with cocaine and suvorexant $(1 \mu \mathrm{M})$. This method allows for detection of spontaneous $\mathrm{Ca}^{2+}$ transients under baseline conditions as well as from pharmacological compound application in vitro.

Statistical analyses. For 5-CSRTT, one-way repeated measures ANOVA with Bonferroni-corrected contrasts against vehicle-treated control groups were used to compare number of premature responses, omissions, latency to retrieve sucrose reward, and accuracy (\# Correct/(\# Correct+\# Incorrect)) as measures of impulsivity. For delay discounting, a two-way ANOVA with Bonferroni-corrected post-hoc tests were used to compare mean number of large rewards chosen at each delay period. For immunohistochemical analyses, oneway ANOVA was used to examine mean estimated proportion of $\mathrm{TH}^{+} / \mathrm{Fos}^{+}$cells and total $\mathrm{Fos}^{+}$cells between treatment groups. Calcium imaging data were analyzed using Bonferroni-corrected t-tests comparing (orexin only, cocaine +orexin+suvorexant) against the orexin+cocaine group.

\section{RESULTS}

\section{Experiment 1A: Suvorexant Attenuates Motor Impulsivity}

Results from the present study revealed a significant main effect of suvorexant on premature responses in 5-CSRTT $(F(2.8,39.9)=2.90, p<0.05$; Figure 1$)$. Contrasts against the vehicle-treated control group found that the $30 \mathrm{mg} / \mathrm{kg}$ suvorexant was effective in reducing premature responses $(p<0.05)$. In a separate cohort of rats, a significant effect of suvorexant $(30 \mathrm{mg} / \mathrm{kg}$, i.p.) on reducing premature responses relative to vehicle pre-treatment was also found (Supplementary Figure 2). No significant effects of TCSOX2-29 on premature responses $(F(2.0,29.2)=2.38$, NS), omissions $(F(2.1,28.8)=2.68$, NS), latency to retrieve sucrose reward $(F(1.7,24.4)=1.42$, NS) or accuracy $(F(1.7$, $22.8)=0.29$, NS) were found. These results support the conclusion that suvorexant has a selective effect on motor impulsivity without interfering with the motivation to consume sucrose rewards.

\section{Experiment 1B: Suvorexant Attenuates Cocaine-Induced Motor Impulsivity by Systemic and Intra-VTA Injection}

A main effect of drug group (vehicle-saline, suvorexantsaline, vehicle-cocaine, and suvorexant-cocaine) on premature responses was found $(F(1.67,23.4)=10.88, p<0.001$; Figures 2,3) Contrasts against vehicle-saline control group revealed that cocaine increased premature responding $(p<0.01)$, but that suvorexant pretreatment normalized cocaine-elicited premature responses to control levels. Neither cocaine nor suvorexant, alone or in combination, had significant effect on omissions $(F(3,55)=1.52$, NS), latency to retrieve sucrose reward $(F(1.9,26.6)=1.02, \mathrm{NS})$ or accuracy $(F(1.7,23.42)=0.67$, NS).

A main effect of drug group on premature responses was additionally observed when suvorexant ( $3 \mu \mathrm{g} / \mathrm{hemisphere)}$ 

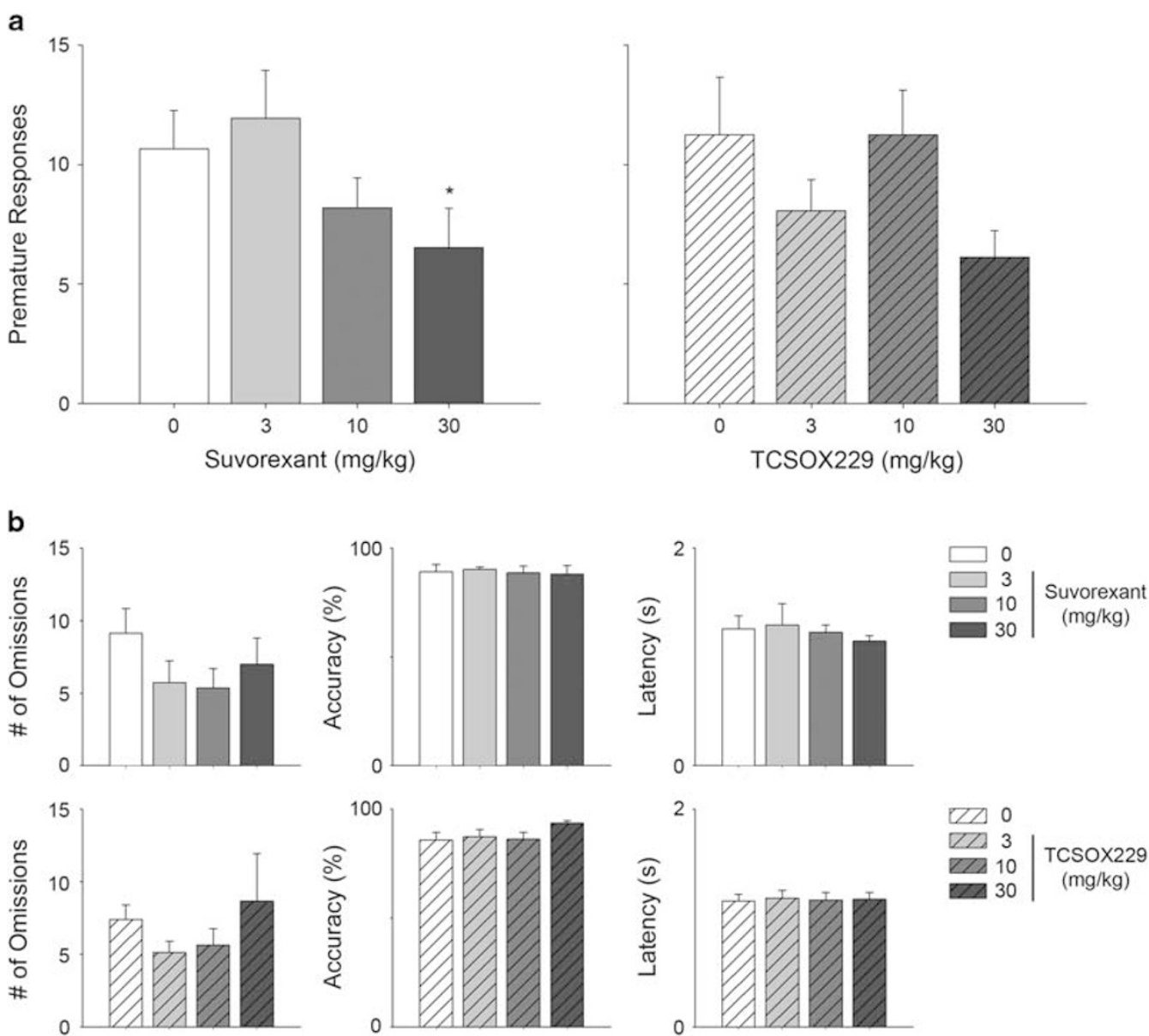

Figure I Effects of suvorexant and TCS-OX2-29 on (a) number of premature responses in 5-CSRTT. Effects of suvorexant and TCS-OX2-29 on (b) number of omissions, \% accuracy and latency to retrieve sucrose reward are also depicted. Data are mean \pm S.E.M. $(n=15-16$ rats per group). * $p<0.05$ compared to the respective $0 \mathrm{mg} / \mathrm{kg}$ group.

was administered into bilateral VTA $(F(1.8,11.1)=9.99$, $p<0.01)$. Post-hoc tests revealed that cocaine increased premature responding relative to the vehicle-saline control group $(p<0.05)$, while suvorexant pretreatment normalized cocaine-elicited premature responses to control levels. Neither cocaine nor suvorexant, alone or in combination, had any significant effect on omissions $(F(1.9,11.23)=0.58$, NS), latency to retrieve sucrose reward $(F(1.2,6.95)=0.76$, NS) or accuracy $(F(1.5,9.13)=1.61, \mathrm{NS})$.

\section{Experiment 2: Orexin Receptor Antagonists Selectively Influence Impulsive Action}

The present study revealed preference for the larger reward (4 sucrose pellets) decreased as delay time increased for all treatment cohorts: SB334867 doses $(F(3,64)=128.70$, $p<0.001)$ suvorexant doses $(F(3,188)=42.45, p<0.001)$ and TCS-OX2-29 doses $(F(3,72)=35.94, \quad p<0.001)$ (Figure 4). Suvorexant did not alter impulsive choice across a dose-response $(F(3,188)=0.91$, NS). TCS-OX2-29 doseresponse revealed a significant main effect $(F(3,72)=4.72$, $p<0.05$ ), but no significant pairwise comparisons were found. At the $10 \mathrm{mg} / \mathrm{kg}$ dose of SB334867 during the nodelay block, rats chose the small-reward option more frequently than the large-reward option $(p<0.01)$.
Experiment 3: Neither Cocaine nor Suvorexant, Alone or in Combination, Alter Fos-ir Within DA-Producing VTA Neurons

A one-way ANOVA examining $\mathrm{TH}^{+}$-Fos ${ }^{+}$neurons in VTA revealed no effect of drug group (vehicle-saline, suvorexantsaline, vehicle-cocaine, suvorexant-cocaine) $(F(3,40)=0.76$, $p>0.05)$. Additionally, no differences in total $\mathrm{Fos}^{+}$neurons in VTA were observed between drug groups $(F(3,40)=0.62$, $p>0.05$; Figure 5a). Finally, no difference in $\mathrm{Fos}^{+}$nuclei of non-TH-labeled cells found (Supplementary Figure 4).

\section{Experiment 4: In vitro Orexin A Potentiates Cocaine-Evoked Calcium Transients within VTA Neurons in a Suvorexant-Sensitive Manner}

Cocaine $(10 \mu \mathrm{M})$ did not elicit an increase in $\left[\mathrm{Ca}^{2+}\right]_{\mathrm{i}}$ within VTA neurons in vitro $\left(\Delta\left[\mathrm{Ca}^{2+}\right]_{\mathrm{i}}=9 \pm 0.6 \mathrm{nM}\right.$; area under curve (AUC) of $\mathrm{Ca}^{2+}$ response $=8.53 \pm 0.7 \mathrm{nM}$ ) (Figure 5). Application of orexin A $(10 \mathrm{nM})$ elevated $\left[\mathrm{Ca}^{2+}\right]_{\mathrm{i}}$ of VTA neurons by $381 \pm 3.7 \mathrm{nM}$ and AUC of $154.75 \pm 2.9 \mathrm{nM}$. Combined administration of cocaine $(10 \mu \mathrm{M}) 10 \mathrm{~min}$ prior to orexin A produced a potentiated increase in $\left[\mathrm{Ca}^{2+}\right]_{\mathrm{i}}(\Delta$ $\left[\mathrm{Ca}^{2+}\right]_{\mathrm{i}}=544 \pm 4.6 \mathrm{nM} ; \quad$ AUC $\left.=304.3 \pm 3.8 \mathrm{Nm}, \quad p<0.001\right)$. The effect of cocaine and orexin A was completely abrogated 

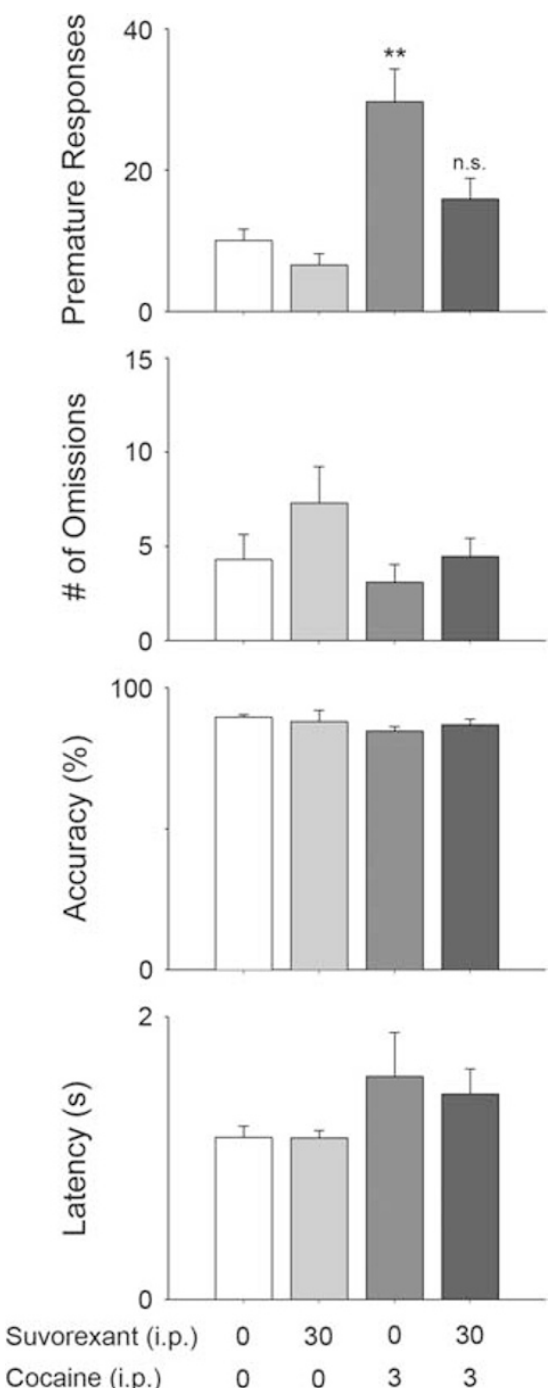

Figure 2 Effects of suvorexant on cocaine-evoked premature responses, number of omissions, \% accuracy and latency to retrieve sucrose reward in 5 -CSRTT ( $n=15$ rats per group). Data are mean \pm S.E.M. ${ }^{*} * p<0.01$ compared to Veh-Sal group.

by pretreatment with suvorexant $(1 \mu \mathrm{M}, 10 \mathrm{~min}): \Delta\left[\mathrm{Ca}^{2+}\right]_{\mathrm{i}}=$ $12 \pm 0.8 \mathrm{nM}$ and $\mathrm{AUC}=29.24 \pm 1.1 \mathrm{nM}$ Amplitude: $(F(3,20)=$ 3914, $p<0.001)$; AUC: $(F(3,20)=9655, p<0.001)$.

\section{DISCUSSION}

We found that the dual orexin receptor antagonist suvorexant attenuates premature responses in the 5-CSRTT a rodent test of motor impulsivity (Bari et al, 2008; Winstanley et al, 2006). Future work will focus on further clarifying the role, if any, of $\mathrm{OX}_{2} \mathrm{R}$ in impulsivity (Hirose et al, 2003). The reductions in premature responding produced by suvorexant are similar to those we have demonstrated using the $\mathrm{OX}_{1} \mathrm{R}$ selective antagonist SB334867 (Muschamp et al, 2014; Porter et al, 2001; Smart et al, 2001), suggesting the effect is mediated by this receptor. These findings are consistent with a dichotomous view of orexin receptor function where $\mathrm{OX}_{1} \mathrm{R}$ regulates motivated behavior and $\mathrm{OX}_{2} \mathrm{R}$ sleep homeostasis (Carter et al, 2013; España et al, 2011; Willie et al, 2003). Importantly and despite the clinical use of suvorexant to treat insomnia (Roecker et al, 2016), reductions in impulsivelike behavior were not due to somnolence or non-specific locomotor decrements. For instance, we observed no increase in the number of trials omitted, subjects' latency to retrieve sucrose rewards, or accuracy even during highdose drug trials. This is seemingly at odds with reports that reflect decreases in open-field ambulation and increased sleep following orexin receptor blockade (Bonaventure et al, 2015; Letavic et al, 2015; Rodgers et al, 2001). The effects we see may be due to higher level of engaging sensory stimulation present in the 5-CSRTT compared to the environment present during tests of open field ambulation. Moreover, in humans and rodents, dual orexin receptor antagonists act primarily to prevent awakening (ie reduced wake after sleep onset) rather than to induce sleep (ie modest effect on sleep latency; Brisbare-Roch et al, 2007). Together, these results suggest that basal orexin tone at $\mathrm{OX}_{1} \mathrm{Rs}$ facilitates prepotent locomotor responses and may mediate impulsivity which itself is characteristic of substance use disorders (reviewed in Alcaraz-Iborra and Cubero, 2015). The decrease in motor impulsivity in the high-dose suvorexant group $(30 \mathrm{mg} / \mathrm{kg}$, i.p. $)$ is modest, and we suspected this to be a product of a 'floor effect' in which baseline (vehicle-pretreatment) premature responses were relatively low. To examine this possibility, we trained a separate cohort of rats, finding that their mean baseline premature responding was higher. Indeed, in this group we were able to resolve a relatively greater reduction in premature responses between vehicle- and suvorexantpretreated groups (Supplementary Figure 2).

While $\mathrm{OX}_{1} \mathrm{R}$ antagonists alone can reduce spontaneous impulsive behavior (Muschamp et al, 2014), their possible clinical utility in mitigating psychostimulant-evoked impulsiveness is also of interest (see: de Wit, 2009). Accordingly, we then tested the extent to which suvorexant could attenuate premature responses evoked by a moderate dose of cocaine. As predicted, cocaine alone produced a two-fold increase in premature responses. This effect was mitigated by suvorexant pretreatment while measures of response capacity (ie omissions, latency, accuracy) again remained unchanged. Taken together, these results support potential clinical utility of orexin receptor antagonists in treating psychiatric disorders characterized by significant trait impulsivity or for transient impulsive behavior engendered by cocaine intoxication. Previous literature implicating the mesolimbic DA pathway in impulsivity coupled with observations of orexin-mediated excitation of VTA DA neurons (Korotkova et al, 2003; Moorman and Aston-Jones, 2010), lead us to hypothesize that it may be an important locus for some forms of impulsivity (Buckholtz et al, 2010; Jentsch and Taylor, 1999; Martin and Potts, 2004; Robbins, 2002). In general agreement with this, systemic cocaine again increased motor impulsivity, while suvorexant infused directly into the VTA attenuated this effect. We targeted a relatively rostral aspect of the VTA in these experiments. The extent to which suvorexant produces similar effects at substructures within the VTA, and potentially opposite effects by acting at adjacent modulatory structures (eg, rostromedial tegmentum, RMTg; Jhou et al, 2009a, b) requires additional study.

Impulsivity is a multidimensional construct encompassing both deficits in response inhibition (ie motor impulsivity) 
a

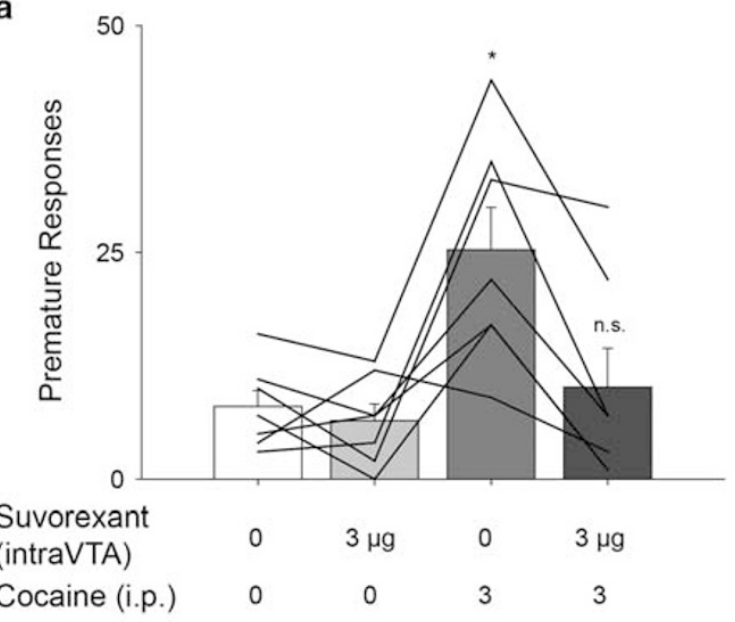

C

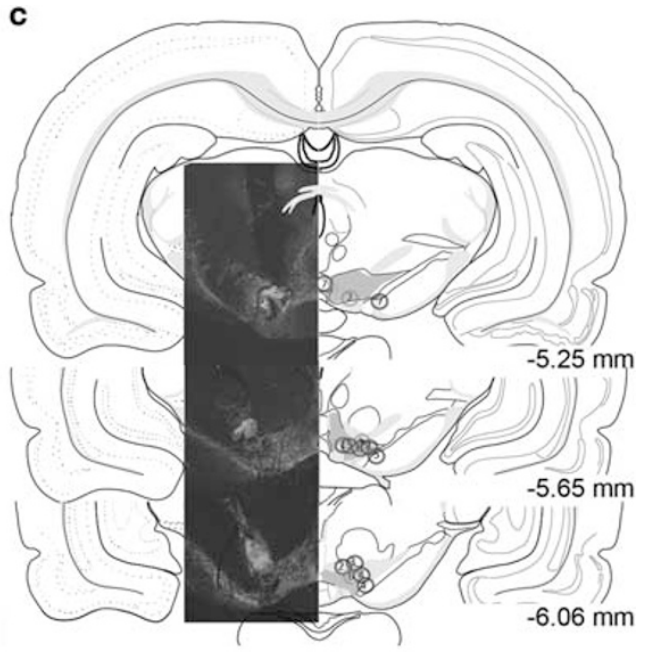

b
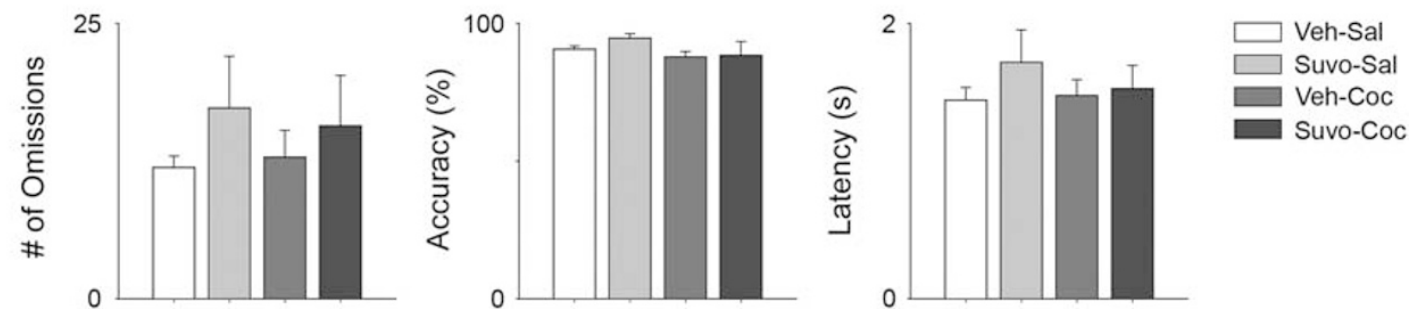

Figure 3 Effects of site-directed suvorexant in the VTA on (a) cocaine-evoked premature responses, (b) number of omissions, \% accuracy and latency to retrieve sucrose reward in 5-CSRTT ( $n=7$ rats per group). (c) Atlas images of cannula placements. Cannula tracks of animals $1-7$ are shown as circles within $\mathrm{TH}^{+}$neurons of the ventral tegmental area. Atlas images taken from Brain Maps III, available online: http://larrywswanson.com/?page_id=I64. Solid lines showing individual animal responses across sessions. Data are mean \pm S.E.M. $* 0<0.05$ compared to vehicle-saline group.

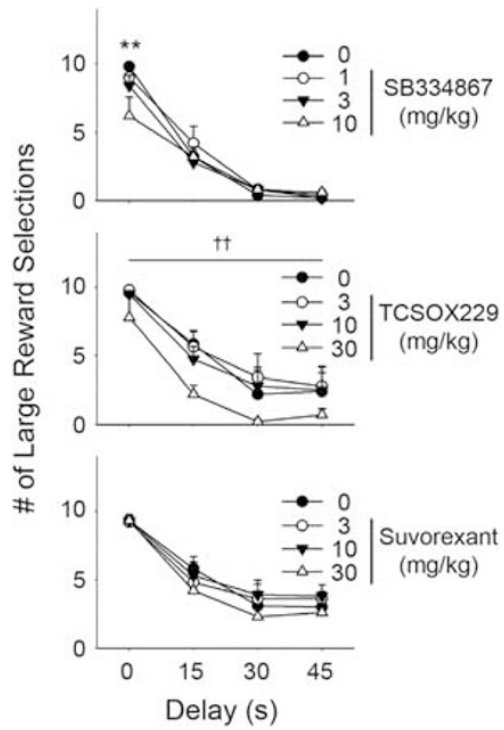

Figure 4 Effects of SB334867, TCS-OX2-29 and suvorexant on large reward options in delay discounting ( $n=5-14$ rats per group). $* * * 0.01$ compared to $0 \mathrm{mg} / \mathrm{kg}$ dose in respective delay block. ${ }^{+{ }^{+}} \mathrm{p}<0.0 \mathrm{I}$ indicates main effect of drug treatment across delay blocks.

and decision-making (eg, delay discounting; Evenden, 1999). To further characterize the possible 'anti-impulsive' profile of orexin receptor antagonists, we used a model of impulsive choice (Robinson et al, 2009). In this task, subjects are prompted to choose between a small sucrose reward available immediately or a larger sucrose reward delivered after a variable delay (15-45s). Preference for the small reward models subjects' impulsivity as they discount the value of the larger reward based on the delay to its receipt. In light of the largely $\mathrm{OX}_{1} \mathrm{R}$-mediated effects of SB334867 and suvorexant on motor impulsivity in the 5-CSRTT, we predicted that these compounds would also increase the number of trials in which rats selected a larger, delayed reward. While subjects satisfied task requirements by completing virtually all trials, neither SB334867 nor suvorexant exerted any appreciable effect on selection of the larger, delayed reward. Interestingly, SB334867 did reduce preference for the larger reward when it was delivered immediately (ie, in the '0-delay' block) and at a frequency narrowly above chance. Because $\mathrm{OX}_{1} \mathrm{Rs}$ are involved in reward processing, including that of palatable food rewards (Borgland et al, 2009; Zheng et al, 2007), this response pattern is interpretable as SB334867-mediated indifference or an 'anhedonia-like' state as has been observed during tasks probing brain reward function (Muschamp et al, 2014). That is, blockade of $\mathrm{OX}_{1}$ Rs may devalue the incentive strength of the large, immediate reward such that even when available immediately, it is chosen no more often than the small reward. The mechanisms underlying this divergent effect are unclear but may derive from the differential expression of $\mathrm{OX}_{1} \mathrm{R}$ and $\mathrm{OX}_{2} \mathrm{R}$ at the gross anatomical level (Marcus et al, 2001). For instance, the paraventricular nucleus of the hypothalamus involved in neuroendocrine function predominantly expresses $\mathrm{OX}_{2} \mathrm{Rs}$, while the prefrontal cortex involved in planning executive function mainly expresses $\mathrm{OX}_{1} \mathrm{R}$. Likewise, at the cellular level the synaptic location 
a
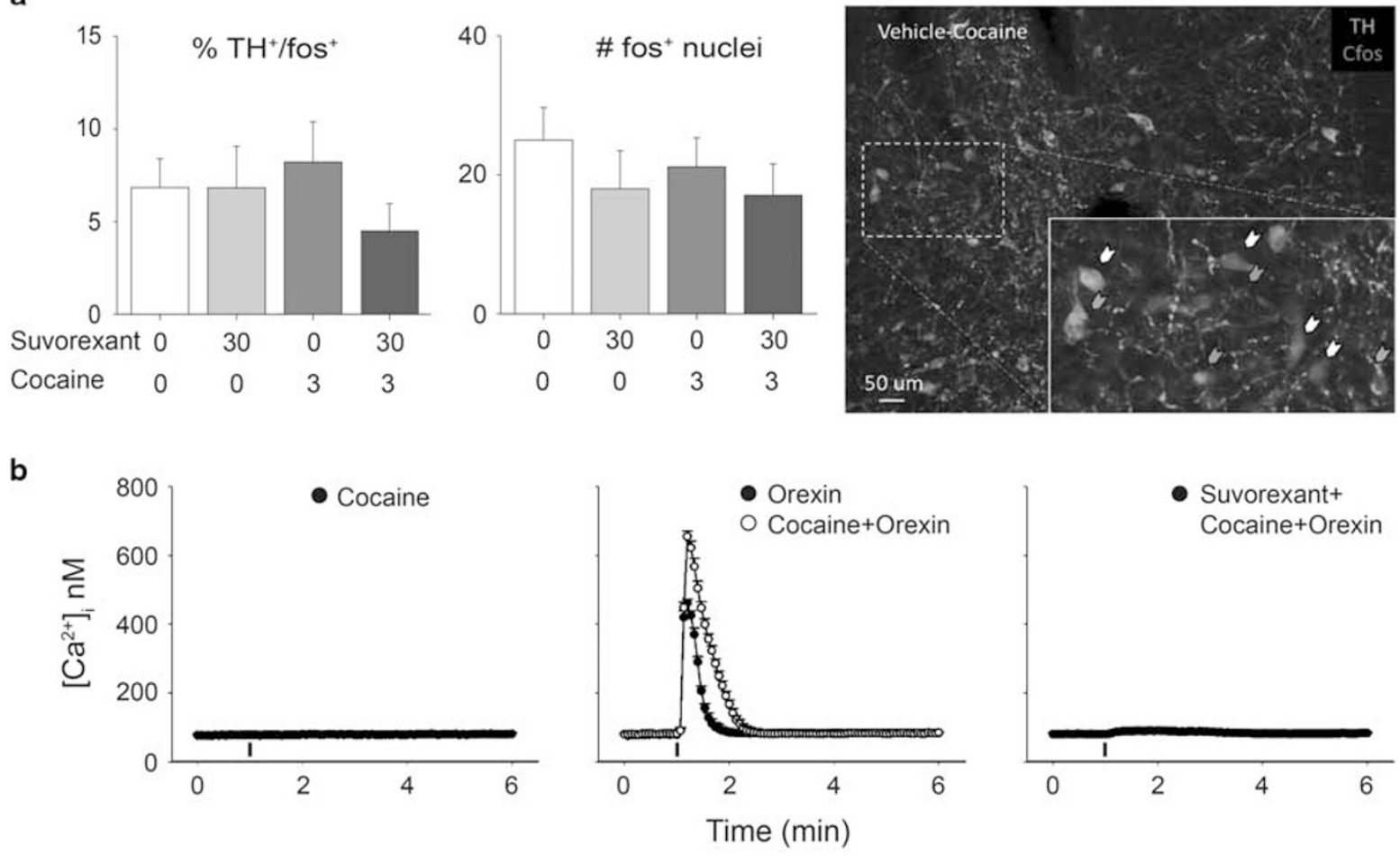

C
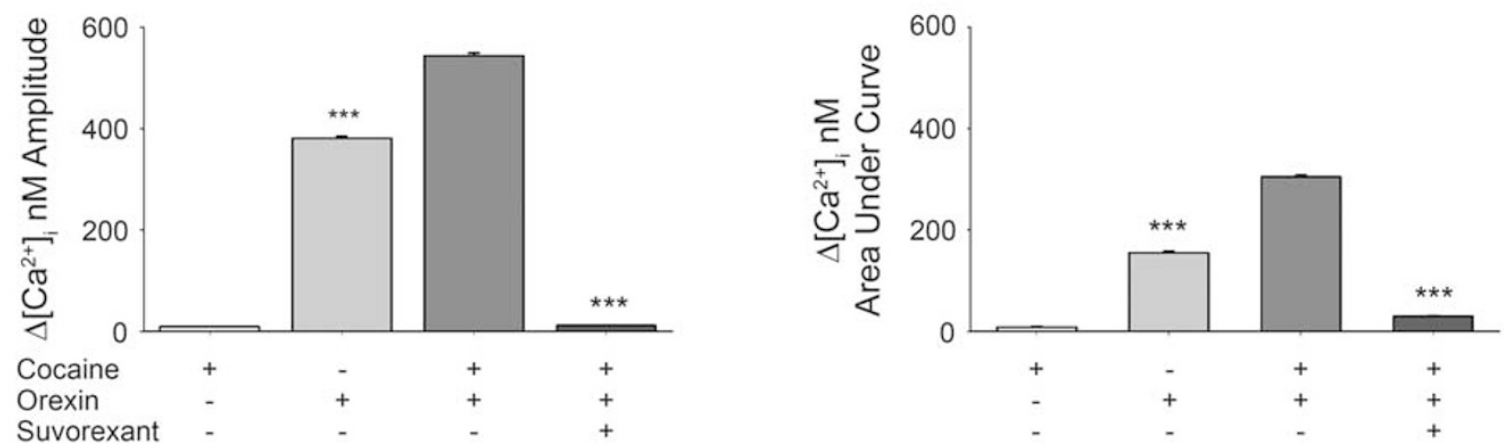

Figure 5 Effects of suvorexant on Fos-ir within VTA DA-producing neurons and cocaine- and orexin-evoked calcium transients within VTA neurons in vitro. (a) \% of total $\mathrm{TH}^{+}$neurons expressing $\mathrm{cFos}^{+}$-ir, average total $\mathrm{TH}^{-}$-cFos ${ }^{+}$counts within $\mathrm{VTA}$ tissue slices and representative photomicrograph of $\mathrm{TH}^{+}{ }^{-} \mathrm{cFos}^{+}$ neurons (white arrows) $\mathrm{TH}^{+}$-Fos (blue arrows) $\mathrm{TH}^{-}$-Fos ${ }^{+}$(orange arrows) in vehicle-pretreated rats. Data in a are mean \pm S.E.M. At $\times 10$ magnification ( $n=4-6$ rats per group). (b) Tracings of VTA Ca ${ }^{2+}$ responses elicited by different cocaine, orexin A, and suvorexant treatments. (c) Comparison of amplitudes and AUCs of $\mathrm{Ca}^{2+}$ responses. Data are expressed as mean \pm S.E.M. ( $n=11-17$ cells per group). $* * * * 2<0.0001$ compared to cocaine+orexin calcium transients. A full color version of this figure is available at the Neuropsychopharmacology journal online.

(ie pre- $v s$ post-) of orexin receptor subtypes in principal or interneurons is incompletely characterized in structures known to play a role in the behaviors we tested.

In light of past literature showing direct excitatory effects of orexins on activity of VTA DA neurons (Korotkova et al, 2003), we sought to quantify differences in Fos-ir within $\mathrm{TH}^{+}$neurons of the VTA after rats were treated with suvorexant alone or in combination with cocaine. Contrary to our expectations, we observed no change in Fos-ir in $\mathrm{TH}^{+}$ neurons of rats in any treatment group. We also saw no increase in Fos-ir nuclei $\left(\mathrm{TH}^{-}\right)$in VTA. Though many authors have reported effects of cocaine or other rewards on Fos-ir in VTA DA neurons, our results are more consistent with reports where robust manipulations (ie rewarding electrical stimulation of afferents to VTA) that evoke marked increases in Fos-ir, fail to do so in $\mathrm{TH}^{+}$neurons of VTA (Hunt and McGregor, 1998; Ishida et al, 2001). It is then plausible that among the many identified immediate early genes expressed by neurons, Fos-ir may not be a reliable marker of neuronal activation in some experimental settings.

With this possibility in mind, we next used a related measure (ie changes in intracellular calcium) to explore the effect of orexin A, suvorexant, or cocaine on VTA neuronal activity. Applied together, we saw that cocaine appears to potentiate the effects of orexin A on intracellular calcium transients in a manner consistent with prior electrophysiology studies examining influence of orexin on VTA DA neurons (Borgland et al, 2006; Korotkova et al, 2003). Notably, we also found that increases in calcium transients produced by orexin A with or without cocaine 
were abolished by suvorexant. While we did not examine effects of suvorexant alone, little basal orexin tone in vitro and absence of reported inverse agonist activity by suvorexant, lead us to expect it would produce no effect on intracellular calcium. Behaviorally relevant doses of cocaine in vivo can produce low- $\mu \mathrm{M}$ concentrations of cocaine in the striatum that amplify $\mathrm{IP}_{3}$ signaling in medium spiny neurons of the NAc (Barr et al, 2015). Both $\mathrm{OX}_{1} \mathrm{R}$ and $\mathrm{OX}_{2} \mathrm{R}$ also use $\mathrm{G}_{\mathrm{q}}$ signaling to generate $\mathrm{IP}_{3}$. Our results raise the possibility of similar signal transduction events in orexin-sensitive VTA neurons. Based on existing in vivo neurochemistry data, these events can be expected to increase the probability of VTA neuronal burst firing and can in turn elevate levels of synaptic DA in NAc (España et al, 2011; Gentile et al, 2017; Overton and Clark, 1997; Prince et al, 2015). Prior central infusion experiments show that pharmacologically-evoked DA release in the NAc results in greater premature responses in the 5-CSRTT (Robbins, 2002).

The effects of orexin receptor antagonists on premature responses in the 5-CSRTT but not on delay discounting suggest a preferential action on motor impulsivity. The reasons for this are not clear but are consistent with data that describe an important role for the orexin system in organizing goal-directed behavioral output. For instance, $\mathrm{OX}_{1} \mathrm{R}$ receptors in VTA can potentiate the excitability of DA neurons elicited during operant acquisition of a food reward (Borgland et al, 2009; Zheng et al, 2007). Electrophysiological recordings of identified orexin neurons in awake, freely moving rats also show that firing rates are highest in active waking, particularly during orienting responses or exploratory behavior (eg, rearing and whisking), and lowest during sleep (Mileykovskiy et al, 2005). The efficient performance of the 5-CSRTT observed here can be readily be described as 'active waking'. We hypothesize that this behavior is typically accompanied by increased orexin transmission. Together, our findings suggest that this pattern of neuronal activity can contribute to increased emission of prepotent goal-directed behaviors. Accordingly, it provides a rationale for further study of suvorexant and similar drugs in treating psychopathologies characterized by impulsive-like behaviors including substance use disorders and ADHD.

\section{FUNDING AND DISCLOSURE}

This work was supported by grants provided by USPHS grants from the National Institute on Drug Abuse and the Margaret Q. Landenberger Research Foundation (R21DA032837, R01DA040693, YZ and RTI; T32DA007237, P30DA013429, R00DA031767, Landenberger Found., JWM and TUSM/ CSAR). The authors declare no conflict of interest.

\section{ACKNOWLEDGMENTS}

We thank Dr Catherine Winstanley at the University of British Columbia for generously sharing MedState scripts used for controlling operant apparatus in delay discounting experiments. Thanks also to Dr Michael Zdilla and Owen O'Sullivin in the Department of Chemistry at Temple University for their kind assistance in chemical authentication of suvorexant by nuclear magnetic resonance.

\section{REFERENCES}

Alcaraz-Iborra M, Cubero I (2015). Do Orexins contribute to impulsivity-driven binge consumption of rewarding stimulus and transition to drug/food dependence? Pharmacol Biochem Behav 134: 31-34.

Arslan G, Filipeanu CM, Irenius E, Kull B, Clementi E, Allgaier C et al (2000). P2Y receptors contribute to ATP-induced increases in intracellular calcium in differentiated but not undifferentiated PC12 cells. Neuropharmacology 39: 482-496.

Bari A, Dalley JW, Robbins TW (2008). The application of the 5choice serial reaction time task for the assessment of visual attentional processes and impulse control in rats. Nat Protoc 3: 759-767.

Barr JL, Deliu E, Brailoiu GC, Zhao P, Yan G, Abood ME et al (2015). Mechanisms of activation of nucleus accumbens neurons by cocaine via sigma-1 receptor-inositol 1,4,5-trisphosphate-transient receptor potential canonical channel pathways. Cell Calcium 58: 196-207.

Bonaventure P, Yun S, Johnson PL, Shekhar A, Fitz SD, Shireman BT et al (2015). A selective orexin-1 receptor antagonist attenuates stress-induced hyperarousal without hypnotic effects. J Pharmacol Exp Ther 352: 590-601.

Borgland SL, Chang SJ, Bowers MS, Thompson JL, Vittoz N, Floresco $\mathrm{SB}$ et al (2009). Orexin A/hypocretin-1 selectively promotes motivation for positive reinforcers. J Neurosci 29: 11215-11225.

Borgland SL, Taha SA, Sarti F, Fields HL, Bonci A (2006). Orexin A in the VTA is critical for the induction of synaptic plasticity and behavioral sensitization to cocaine. Neuron 49: 589-601.

Boschen KE, Fadel JR, Burk JA (2009). Systemic and intrabasalis administration of the orexin-1 receptor antagonist, SB-334867, disrupts attentional performance in rats. Psychopharmacology (Berl) 206: 205-213.

Brisbare-Roch C, Dingemanse J, Koberstein R, Hoever P, Aissaoui $\mathrm{H}$, Flores S et al (2007). Promotion of sleep by targeting the orexin system in rats, dogs and humans. Nat Med 13: 150-155.

Buckholtz JW, Treadway MT, Cowan RL, Woodward ND, Li R, Ansari MS et al (2010). Dopaminergic network differences in human impulsivity. Science 329: 532.

Carter ME, de Lecea L, Adamantidis A (2013). Functional wiring of hypocretin and LC-NE neurons: implications for arousal. Front Behav Neurosci 7: 43.

Dalley J, Mar A, Economidou D, Robbins T (2008). Neurobehavioral mechanisms of impulsivity: Fronto-striatal systems and functional neurochemistry. Pharmacology Biochemistry and Behavior 90: 250-260.

de Lecea L, Kilduff TS, Peyron C, Gao X, Foye PE, Danielson PE et al (1998). The hypocretins: hypothalamus-specific peptides with neuroexcitatory activity. Proc Natl Acad Sci USA 95: 322-327.

de Wit H (2009). Impulsivity as a determinant and consequence of drug use: a review of underlying processes. Addict Biol 14: 22-31.

España RA, Melchior JR, Roberts DC, Jones SR (2011). Hypocretin 1/orexin $\mathrm{A}$ in the ventral tegmental area enhances dopamine responses to cocaine and promotes cocaine self-administration. Psychopharmacology (Berl) 214: 415-426.

Evenden JL (1999). Varieties of impulsivity. Psychopharmacology (Berl) 146: 348-361.

Fadel J, Deutch AY (2002). Anatomical substrates of orexindopamine interactions: lateral hypothalamic projections to the ventral tegmental area. Neuroscience 111: 379-387.

Gentile TA, Simmons SJ, Barker DJ, Shaw JK, España RA, Muschamp JW (2017). Suvorexant, an orexin/hypocretin receptor antagonist, attenuates motivational and hedonic properties of cocaine. Addict Biol (e-pub ahead of print).

Harris GC, Wimmer M, Aston-Jones G (2005). A role for lateral hypothalamic orexin neurons in reward seeking. Nature 437: 556-559.

Hirose M, Egashira S, Goto Y, Hashihayata T, Ohtake N, Iwaasa H et al (2003). $\mathrm{N}$-acyl 6,7-dimethoxy-1,2,3,4-tetrahydroisoquinoline: 
the first orexin-2 receptor selective non-peptidic antagonist. Bioorg Med Chem Lett 13: 4497-4499.

Hunt GE, McGregor IS (1998). Rewarding brain stimulation induces only sparse Fos-like immunoreactivity in dopaminergic neurons. Neuroscience 83: 501-515.

Ishida Y, Nakamura M, Ebihara K, Hoshino K, Hashiguchi H, Mitsuyama $Y$ et al (2001). Immunohistochemical characterisation of Fos-positive cells in brainstem monoaminergic nuclei following intracranial self-stimulation of the medial forebrain bundle in the rat. Eur J Neurosci 13: 1600-1608.

Jentsch JD, Taylor JR (1999). Impulsivity resulting from frontostriatal dysfunction in drug abuse: implications for the control of behavior by reward-related stimuli. Psychopharmacology (Berl) 146: 373-390.

Jhou TC, Fields HL, Baxter MG, Saper CB, Holland PC (2009a). The rostromedial tegmental nucleus (RMTg), a GABAergic afferent to midbrain dopamine neurons, encodes aversive stimuli and inhibits motor responses. Neuron 61: 786-800.

Jhou TC, Geisler S, Marinelli M, Degarmo BA, Zahm DS (2009b). The mesopontine rostromedial tegmental nucleus: a structure targeted by the lateral habenula that projects to the ventral tegmental area of Tsai and substantia nigra compacta. J Comp Neurol 513: 566-596.

Kessler RC, Adler LA, Berglund P, Green JG, McLaughlin KA, Fayyad J et al (2014). The effects of temporally secondary co-morbid mental disorders on the associations of DSM-IV ADHD with adverse outcomes in the US National Comorbidity Survey Replication Adolescent Supplement (NCS-A). Psychol Med 44: 1779-1792.

Khoo SY, Brown RM (2014). Orexin/hypocretin based pharmacotherapies for the treatment of addiction: DORA or SORA? CNS Drugs 28: 713-730.

Korotkova TM, Sergeeva OA, Eriksson KS, Haas HL, Brown RE (2003). Excitation of ventral tegmental area dopaminergic and nondopaminergic neurons by orexins/hypocretins. J Neurosci 23: 7-11.

Lambe EK, Olausson P, Horst NK, Taylor JR, Aghajanian GK (2005). Hypocretin and nicotine excite the same thalamocortical synapses in prefrontal cortex: correlation with improved attention in rat. J Neurosci 25: 5225-5229.

Letavic MA, Bonaventure P, Carruthers NI, Dugovic C, Koudriakova T, Lord B et al (2015). Novel Octahydropyrrolo[3,4-c]pyrroles are Selective Orexin-2 Antagonists: SAR Leading to a Clinical Candidate. J Med Chem 58: 5620-5636.

Lopez-Torrecillas F, Perales JC, Nieto-Ruiz A, Verdejo-Garcia A (2014). Temperament and impulsivity predictors of smoking cessation outcomes. PLOS ONE 9: e112440.

Marcus JN, Aschkenasi CJ, Lee CE, Chemelli RM, Saper CB, Yanagisawa $M$ et al (2001). Differential expression of orexin receptors 1 and 2 in the rat brain. J Comp Neurol 435: 6-25.

Martin LE, Potts GF (2004). Reward sensitivity in impulsivity. Neuroreport 15: 1519-1522.

Mileykovskiy BY, Kiyashchenko LI, Siegel JM (2005). Behavioral correlates of activity in identified hypocretin/orexin neurons. Neuron 46: 787-798.

Moorman DE, Aston-Jones G (2010). Orexin/hypocretin modulates response of ventral tegmental dopamine neurons to prefrontal activation: diurnal influences. J Neurosci 30: 15585-15599.

Muschamp JW, Dominguez JM, Sato SM, Shen RY, Hull EM (2007). A role for hypocretin (orexin) in male sexual behavior. J Neurosci 27: 2837-2845.

Muschamp JW, Hollander JA, Thompson JL, Voren G, Hassinger LC, Onvani S et al (2014). Hypocretin (orexin) facilitates reward by attenuating the antireward effects of its cotransmitter dynorphin in ventral tegmental area. Proc Natl Acad Sci USA 111: E1648-E1655.
Ongur D, Price JL (2000). The organization of networks within the orbital and medial prefrontal cortex of rats, monkeys and humans. Cereb Cortex 10: 206-219.

Overton PG, Clark D (1997). Burst firing in midbrain dopaminergic neurons. Brain Res Brain Res Rev 25: 312-334.

Peyron C, Tighe DK, van den Pol AN, de Lecea L, Heller HC, Sutcliffe JG et al (1998). Neurons containing hypocretin (orexin) project to multiple neuronal systems. J Neurosci 18: 9996-10015. Porter RA, Chan WN, Coulton S, Johns A, Hadley MS, Widdowson $\mathrm{K}$ et al (2001). 1,3-Biarylureas as selective non-peptide antagonists of the orexin-1 receptor. Bioorg Med Chem Lett 11: 1907-1910.

Prince CD, Rau AR, Yorgason JT, España RA (2015). Hypocretin/ Orexin regulation of dopamine signaling and cocaine self-administration is mediated predominantly by hypocretin receptor 1. ACS Chem Neurosci 6: 138-146.

Robbins TW (2002). The 5-choice serial reaction time task: behavioural pharmacology and functional neurochemistry. Psychopharmacology (Berl) 163: 362-380.

Robinson ES, Eagle DM, Economidou D, Theobald DE, Mar AC, Murphy ER et al (2009). Behavioural characterisation of high impulsivity on the 5-choice serial reaction time task: specific deficits in 'waiting' versus 'stopping'. Behav Brain Res 196: 310-316.

Rodgers RJ, Halford JC, Nunes de Souza RL, Canto de Souza AL, Piper DC, Arch JR et al (2001). SB-334867, a selective orexin-1 receptor antagonist, enhances behavioural satiety and blocks the hyperphagic effect of orexin-A in rats. Eur J Neurosci 13: 1444-1452.

Roecker AJ, Cox CD, Coleman PJ (2016). Orexin receptor antagonists: new therapeutic agents for the treatment of insomnia. J Med Chem 59: 504-530.

Sakurai T (2014). The role of orexin in motivated behaviours. Nat Rev Neurosci 15: 719-731.

Sakurai T, Amemiya A, Ishii M, Matsuzaki I, Chemelli RM, Tanaka H et al (1998). Orexins and orexin receptors: a family of hypothalamic neuropeptides and $G$ protein-coupled receptors that regulate feeding behavior. Cell 92: 573-585.

Scammell TE, Winrow CJ (2011). Orexin receptors: pharmacology and therapeutic opportunities. Annu Rev Pharmacol Toxicol 51: 243-266.

Smart D, Sabido-David C, Brough SJ, Jewitt F, Johns A, Porter RA et al (2001). SB-334867-A: the first selective orexin-1 receptor antagonist. Br J Pharmacol 132: 1179-1182.

Swann AC (2010). Mechanisms of impulsivity in bipolar disorder and related illness. Epidemiol Psichiatr Soc 19: 120-130.

Vall G, Gutierrez F, Peri JM, Garriz M, Ferraz L, Bailles E et al (2015). Seven basic dimensions of personality pathology and their clinical consequences: are all personalities equally harmful? Br J Clin Psychol 54: 450-468.

Willie JT, Chemelli RM, Sinton CM, Tokita S, Williams SC, Kisanuki YY et al (2003). Distinct narcolepsy syndromes in Orexin receptor-2 and Orexin null mice: molecular genetic dissection of Non-REM and REM sleep regulatory processes. Neuron 38: 715-730.

Winstanley CA, Eagle DM, Robbins TW (2006). Behavioral models of impulsivity in relation to ADHD: translation between clinical and preclinical studies. Clin Psychol Rev 26: 379-395.

Zheng H, Patterson LM, Berthoud HR (2007). Orexin signaling in the ventral tegmental area is required for high-fat appetite induced by opioid stimulation of the nucleus accumbens. J Neurosci 27: 11075-11082.

Zhu Y, Miwa Y, Yamanaka A, Yada T, Shibahara M, Abe Y et al (2003). Orexin receptor type-1 couples exclusively to pertussis toxin-insensitive G-proteins, while orexin receptor type-2 couples to both pertussis toxin-sensitive and -insensitive G-proteins. J Pharmacol Sci 92: 259-266.

Supplementary Information accompanies the paper on the Neuropsychopharmacology website (http://www.nature.com/npp) 